\title{
La transformación del ḥiṣn andalusí de Ṭaybāliya en un castillo santiaguista de frontera
}

The transformation of the Andalusian fortress of Taibilla into a feudal border castle

\author{
Pedro Jiménez Castillo a ${ }^{\text {, Francisco J. Muñoz López }}{ }^{\text {b }}$ \\ a Laboratorio de Arqueología y Arquitectura de la Ciudad - Escuela de Estudios Árabes - Consejo Superior de \\ Investigaciones Científicas, Granada, Spain, pedro@eea.csic.es \\ ${ }^{\mathrm{b}}$ Archaeologist, Nerpio, Spain, pacoarqueologo@ hotmail.com
}

\begin{abstract}
In this paper, we will study the fortress of Taibilla, a defensive complex built by the Order of Santiago in the middle of the thirteenth century in a strategic point of the Sierra de Segura, currently belonging to the municipality of Nerpio (Albacete). Although the complex was built at the top of the hill on whose hillside a relatively important town existed in Andalusian times, the archaeological excavations proved that most of the remains of the fortification currently visible were built after the Christian conquest. It is a stately castle and the outer enclosure that protected the Christian town, both of notable importance since they were destined to accommodate a comendador and a council respectively. The Encomienda de Taibilla, however, disappeared within a few years due to the avatars of the border, leaving its territory incorporated to that of Yeste. For this reason, the fortress of Taibilla hardly underwent modifications in the medieval period, so that it has been fossilized as an excellent example of the santiaguista stately architecture of the middle of the thirteenth century.
\end{abstract}

Keywords: Al-Andalus, Castilla, Order of Santiago, Taibilla, Sierra de Segura.

\section{Introducción}

La fortaleza de Taibilla se encuentra situada en el municipio de Nerpio (Albacete), en el corazón de la Sierra de Segura, un macizo montañoso perteneciente a la Cordillera Bética, en la transición entre la Meseta y las tierras bajas del Sureste de la Península Ibérica. El territorio se caracteriza por la altitud de sus montañas y altiplanicies, la profusión de ríos y arroyos, así como abundantes valles encajonados en esos cursos fluviales. El conjunto defensivo fue construido en una elevación y junto a un valle angosto que forma parte de una ruta que comunicaba los reinos históricos de Granada y Murcia a través la comarca natural del Alto Segura. En la ladera norte se distinguen restos de un caserío de exten-

sión y densidad indeterminadas; se trata principalmente de arranques de muros de mampostería y cerámicas en superficie mayoritariamente de época islámica. La fortaleza, situada en lo alto del collado, consta de una gran torre del homenaje a la que se adosa un recinto rectangular, el cortijo, todo ello protegido por su lado norte por un lienzo de muralla exterior que se adapta a la orografía del cerro y, por el sur, por un acantilado natural. Este conjunto defensivo fue construido hacia mediados del siglo XIII, cuando la Orden de Santiago estableció en Taibilla la cabeza de una encomienda que solo pervivió apenas un siglo. 


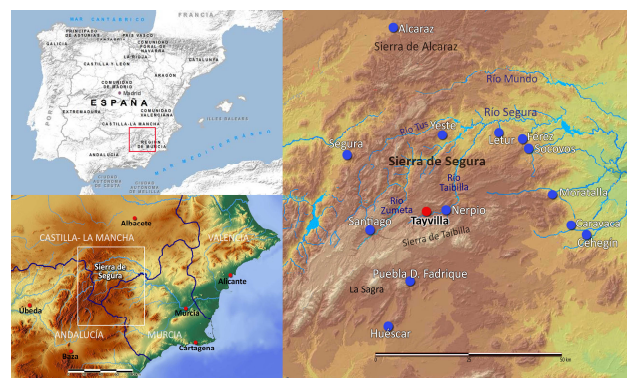

Fig. 1. Situación de la Sierra de Segura.

\section{Historia}

La Sierra de Segura era un territorio densamente poblado que, tal como refirió en el siglo XII alZuhrī, tenía 300 alquerías y 33 castillos (HadjSadok, 1968, p. 209). Se sustentaba la población sobre una base económica agropecuaria donde, no obstante, prevalecía la ganadería (Huici Miranda, 1969, p. 81), tal como ha sido en los últimos quinientos años. El tipo y tamaño de estos sitios se enmarca dentro de una horquilla amplia, desde cuevas-refugio de pastores, alquerías y hușūn, o poblaciones medianas fortificadas $^{1}$, entre las que destacaba Taybāliya (Simón García, 2016, pp. 661-663).

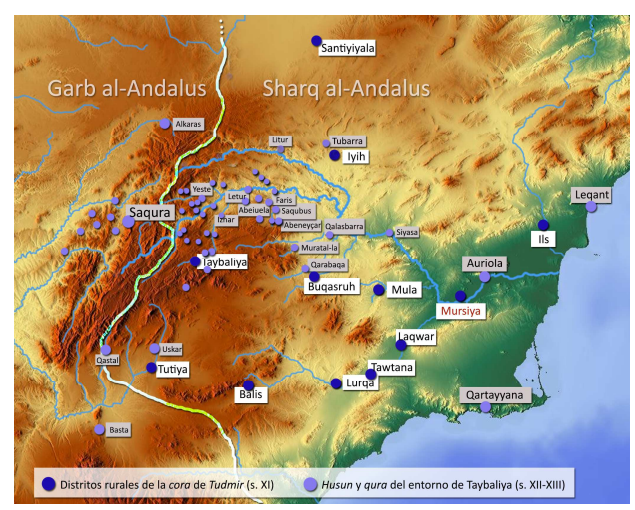

Fig. 2. La cora de Tudmīr entre los siglos XI y XIII.

Țaybāliya fue en el siglo XI cabeza de unos de los diecisiete distritos rurales (iqlimm) de la cora de Tudmīr, el único en esta Sierra. Limitaba con los de Iyih al-Sahal (El Tolmo de Minateda, Hellín) por el norte, Buqasru (Begastri, Cehegín) por el este, Tūtiya (Galera) por el suroeste y Bališ (Vélez) por el sur; por el oeste limitaba con el distrito de Segura, de la cora de Jaén
(Vallvé Bermejo, 1972, pp. 155-56; Molina López, 1972). Dentro de su jurisdicción quedarían los ḥușūn de Iznar (Dehesa de Letur), Letur, Šaqūbū (Socovos), Fariṣ (Férez) y tal vez los de Abeneyçar (Benizar) y Priego. En la Țaybāliya del siglo XII nació algún personaje de relevancia como Muhammad b. 'Abd al-Malik b. Abū Nadir, que fue juez en Almería y que tuvo como maestro en Țaybāliya al predicador Ma'zuz $b$. Habid al-Țaybāli, según se recoge en la Takmila (Guichard, 1991, pp. 41, 59).

Tras la batalla de las Navas de Tolosa, los ejércitos de Alfonso VIII y los del arzobispo de Toledo, don Rodrigo Ximénez de Rada, tomaron en 1213 las villas de Alcaraz y Riópar, y Segura en 1214, llevando así la línea de frontera al límite septentrional de las tierras de Yeste, aunque el hambre y las treguas frenaron, temporalmente, el avance castellano ${ }^{2}$ (Chaves, 1740, p. 194b; Torres Fontes, 1965-1966, p. 34, ss.; Rivera Garretas, 1985, p. 401, Doc. 193; Rodríguez Llopis, 1985; López Fernández, 2004, p. 36).

En torno a 1235 la Orden santiaguista se había apoderado de buena parte de la mitad occidental de la Sierra, de los lugares de Torres de Albánchez, Génave, Bayona y Villarrodrigo. Entre 1239 y 1242 se produciría la ocupación de Hornos, Siles, Benatae y Orcera, a la vez que el maestre don Rodrigo Yáñez consiguió la posesión de Hornos (Torres Fontes, 1965, p. 326).

En 1241, las milicias santiaguistas vencieron varias fortalezas, entre ellas Huéscar, Galera y Orce, es decir, las tierras limítrofes con Yeste, Taibilla y Caravaca, con la idea de continuar hacia el sur sin penetrar en el reino murciano (Torres Fontes, 1965, pp. 326-327). Mientras esto ocurría, tropas castellanas tomaban Albacete y las milicias santiaguistas, al mando del comendador mayor don Pelay Pérez Correa, preparaban una expedición contra Chinchilla, que fue tomada a principios de 1242. Parte de este ejército al mando de Gil Gómez D’Ovinhal, uno de los caballeros portugueses venidos a Castilla junto a Pérez Correa, se dirigió hacia el sur conquistando los castillos de Híjar, Vicorto, Villares y Abejuela (Rivera Garretas, 1985, p. 401, doc. 193); esta expedición debió penetrar por Liétor a la comarca del alto Segura: Letur, 
Férez, Socovos Yeste y Taibilla. En agosto del mismo año Fernando III otorgaba a la Orden de Santiago la villa de Segura cum omnibus terminis suis. El 5 de julio de 1243, el infante don Alfonso, a petición del nuevo maestre don Pelay Pérez, confirmaba a la Orden la posesión de la villa de Segura "cum omnibus terminis suis nouis et antiquis; cum castellis hic connominatus vidalecit: Muratalla, Socouos, Bueycorto, Gutta, Letur, Priego, Feriz, Abeiula, Litur, Aznar, Abeneycar, Nerpe, Tayviella, Yeste, Agraya, Catena, Albanchez, Huescar, Mirauet, Vulteyrola, Burgeia"3.

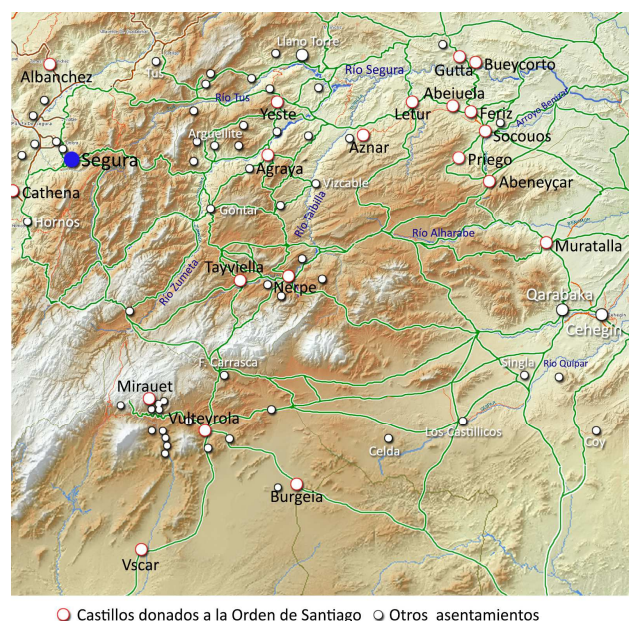

Fig. 3. Poblamiento en el Alto Segura y su entorno en mitad del siglo XIII.

Cuando en 1243 el reino de Murcia se sometió al infante don Alfonso de Castilla, la Orden de Santiago era ya dueña de una amplia comarca con centro en Segura de la Sierra, comprendiendo desde el Yelmo hasta Moratalla, y que incluía, entre otras muchas, las poblaciones de Yeste, Taibilla, Nerpio, Góntar o La Graya. Muy extensa era, por tanto, este territorio y prácticamente imposible de controlar y defender, por lo que fue fragmentado con la formación de nuevas encomiendas en lo que antes había sido el vasto término de Segura. Este hecho ocurrió en 1245 al trasladarse a esta villa la encomienda mayor de la Orden de Santiago, a la vez que poblaciones como Moratalla, Socovos, Taibilla y Yeste hasta entonces pertenecientes a Segura- conseguían sus respectivos privilegios de villazgo y se conformaban como encomiendas autónomas (Rodríguez Llopis, 1982, p. 37; 1991). La encomienda de Taibilla englobaba el paraje de Góntar, si bien le sería arrebatada por Yeste algún tiempo después de la desaparición de la frontera. Taibilla conservaba por el suroeste un paso relativamente fácil hacia Huéscar, en la frontera granadina, un camino que no por difícil dejó de ser frecuentado a lo largo de dos siglos y medio en continuas incursiones depredadoras.

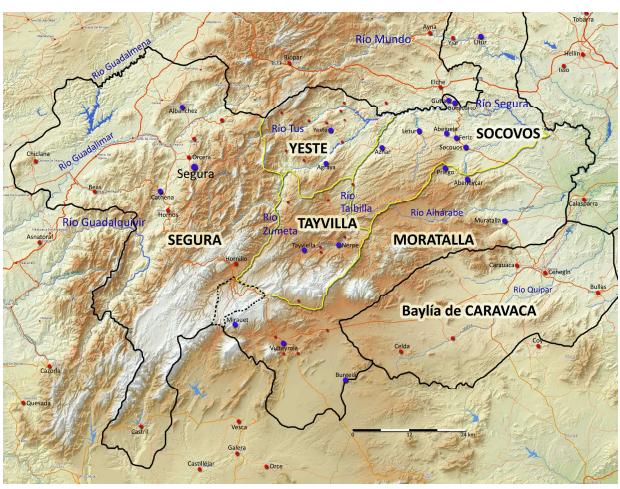

Fig. 4. Partido de Segura de la Sierra y encomiendas santiaguistas.

Inicialmente la población musulmana se mantuvo en el conjunto del territorio serrano, aunque su proporción variaba de unas encomiendas a otras. Parece ser que su porcentaje fue mucho mayor en Socovos, villa que todavía a inicios del siglo XVI era descrita como "castillo de moros". Taibilla mantuvo también la población musulmana, mientras que la población mudéjar de Yeste fue poco a poco desplazándose del núcleo fortificado. Está documentada la permanencia de musulmanes en Yeste, Taibilla, Góntar y La Graya en todo el siglo XIII, y de ellos recibía la Orden de Santiago en 1273 y 1274 importantes ingresos en concepto de alfardas y otros impuestos. La necesidad de repoblar de manera rápida y efectiva esta comarca fronteriza impulsó a Don Pelay Pérez Correa a dotarla de un fuero ventajoso, el de Cuenca, que se aplicaba normalmente a las tierras de realengo. A pesar de ello, los nuevos pobladores fueron acudiendo en número escaso y el aumento demográfico fue débil a lo largo de los siglos XIII y XIV. Según Rodríguez Llopis, todas las fuentes permiten deducir una 
desaparición paulatina de mudéjares desde fines del siglo XIII de los núcleos principales de Yeste y Taibilla, a la vez que desaparecían casi la totalidad de asentamientos menores.

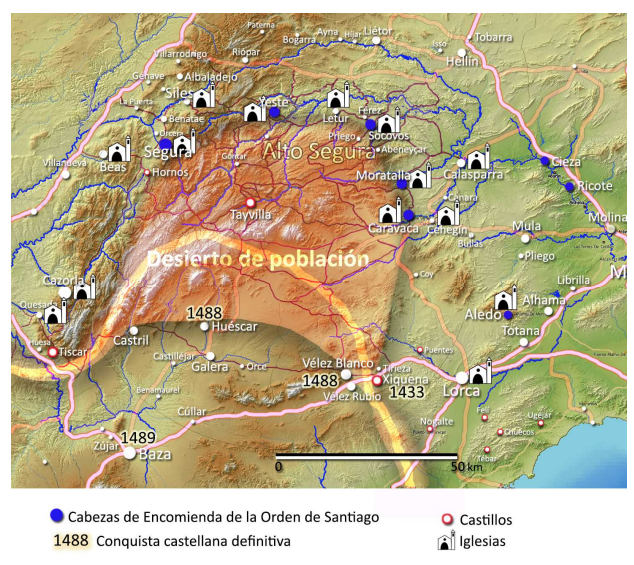

Fig. 5. La frontera murciano-granadina en el último cuarto del siglo XV.

La peremne crisis demográfica y la presión nazarí están en el origen de los intentos de Fernando IV y del maestre de Santiago don Fernando Osórez en 1303 para lograr una bula papal que autorizase la cruzada para la recogida de fondos destinados al "mantenimiento de la Frontera è de los Caftiellos de Huefca, è de Orça, è de Caftiel de Galera, è de Benamexir, è de Eftepa, è de Tayviella, è de Aledo è de Ricote è de la Peña è de Moratalla, que fon en Frontera de Moros [...]"4 (Aguado de Córdoba, Alemán et Rosales, López Agurleta, 1719, pp. 249-250). Aparte de esta bula, apenas tenemos referencias documentales sobre Taibilla salvo las descripciones de los visitadores de la Orden de Santiago de la segunda mitad del siglo XV. En este sentido, es significativa su ausencia en otros documentos posteriores, como una carta real fechada en 1349 en la que sí se recogen sitios como Socovos, Yeste, Letur o Carava (Rodríguez Llopis, 1986a, p. 34, nota $86 ; 1986$ b); o la bula papal de 1386 , donde vuelven a ser nombrados lugares como Yeste, Socovos, Moratalla, Priego o Benizar (Aguado de Córdoba, et al., 1719, pp. 354-5). La aparición de las sucesivas oleadas de peste desde mediados del siglo XIV debieron de ocasionar en el término de Taibilla una fuerte disminución de habitantes, lo que sumado a la pérdida de Huéscar en 1334, que llevó los límites fronterizos al sur del término de Taibilla, provocaría el total abandono de la villa y término durante la segunda mitad de siglo. El último comendador de Taibilla que tenemos documentado es Juan Cano en 1409 y es posible que fuera pocos años después cuando la encomienda quedó unida a la de Yeste bajo la denominación de encomienda de "Yeste y Taibilla" (Rodríguez Llopis, 1982, p. 38). A partir de este momento, la administración del término de Taibilla la llevó el comendador de Yeste a través del alcaide de la fortaleza y del alguacil de términos de Taibilla.

\section{El despoblado de Ṭaybāliya}

Țaybāliya se situaba en un cerro de gran extensión y altura, en acantilado de $70 \mathrm{~m}$ por el lado sur, el del río Taibilla, y con ladera suave y accesible en la vertiente norte. En la parte superior amesetada se encontraba el albacar, cerrado con un lienzo de muralla longitudinal en sentido oeste-este. En la ladera norte de la montaña sobre la que se extendía el poblado aparecen abundantes restos cerámicos de época andalusí en una superficie aproximada de 3,7 hectáreas incluida el espacio ocupado por la fortaleza cristiana. De los siglos XVII y XVIII conocemos descripciones de restos de edificaciones. Unas que fueron desenterradas en 1604 (Rodríguez Llopis, 1995, pp. 13, ss), "donde parezia auer señales y uestigios de tenplo [...] y ansi mismo se hallaron munchos pedazos de yeso labrados con lauores y molduras con colores y otros muy reçios que pareçian ser de la ruina de las arcadas o bouedas [...]"; nosotros creemos que en realidad lo que descubrieron fue una mezquita, y los yesos labrados con labores y molduras con colores son yeserías policromadas decorativas de vanos y ventanas. Esta otra descripción fue publicada en 1794 por el clérigo Juan Lozano Santa5: "Al ocaso, pues de este castillo y en la planicie misma, están de manifiesto las reliquias de población [...] La extensión de sus vestigios es considerable. Su latitud y longitud como de media legua. Todo a la falda del castillo".

Asimismo, a unos trescientos metros de la alquería, al borde del camino que lleva a Jutia y 
Yeste, se localiza el cementerio, del cual tenemos referencias por remociones agrícolas del terreno, con la aparición de huesos y losas de piedra trabajadas, además de por la localización de una lápida con grafía árabe.

\section{Descripción de la fortaleza ${ }^{6}$}

En la parte alta del cerro de forma oblonga, a una altura de 1255 m.s.n.m., se localizan los restos defensivos compuestos por dos ámbitos bien definidos: el recinto exterior y el castillo. El primero, al que se accede por un camino angosto en parte tallado en la roca, es un espacio de aproximadamente $5500 \mathrm{~m}^{2}$, delimitado al norte por un recinto de tapial de hormigón y al sur por un impresionante acantilado. La muralla, bastante deteriorada y con tramos perdidos por completo, está compuesta por un zócalo de cal y canto sobre el que se apoya el alzado de argamasa encofrada, rematado por un parapeto en el que se practican saeteras y, sobre él, la hilada de almenas. En este perímetro se abre una puerta en recodo, integrada en una torre rectangular, que hemos denominado Puerta Noroeste. Protegida por un parapeto, está cerrada por una bóveda de cañón fabricada con mampostería tomada con cal, que reposa sobre los muros de tapial. Las dos aberturas que presenta corresponden sin duda a los dos vanos con que contaba, desalineados para crear un acceso acodado y flanqueados por jambas de mampostería. Conformando otra ancha torre, se edificó en el recinto un aljibe en tapial con dos naves comunicadas por un arco y cubiertas por sendas bóvedas.

La cerca antes descrita acoge en su interior otro recinto, en este caso de planta regular, del que forma parte la Torre del Homenaje. Este espacio rectangular, denominado "cortijo" en las visitaciones santiaguistas, está compuesto por tres crujías en torno a un patio, mientras que en el cuarto frente, el oriental, se alza la Torre y la puerta de entrada a este recinto acompañada por otra pequeña torre. En el centro del patio, aproximadamente, se encuentran los restos de un aljibe de dos cámaras cuya bóveda estaba completamente hundida. Sobre este aljibe se construyó en algún momento entre 1480 y 1494 la ermita de Santa María de Taibilla. Se conservan en estado aceptable los muros externos de los lados norte y oeste del cortijo, gracias a lo cual sabemos que tenía una base de mampostería en hiladas, alzado de tapial calicastrado, con adarve sobre andamio, pretil con saeteras y almenas en piramidón, idéntico, en cuanto a técnica y materiales constructivos, que el muro exterior, aunque sensiblemente menos espeso.

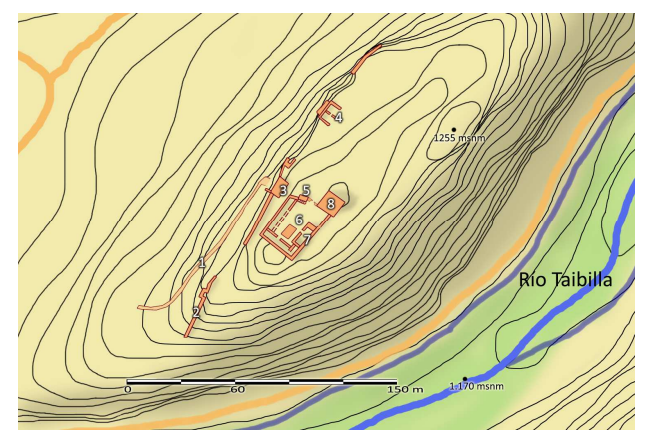

Fig. 6. Planta de la fortaleza. 1) Camino de subida; 2) Muralla exterior; 3) Puerta noroeste; 4) Aljibes del albacar; 5) Frente este; 6) Patio y ermita; 7) Crujía sur; 8) Torre del Homenaje.

Gracias a la excavación arqueológica llevada a cabo desde 2004 sabemos que el cortijo tuvo una primera puerta en el extremo norte del frente oriental; era gótica, con arco apuntado, y fue cegada a finales del siglo XV cuando se abrió la puerta nueva. Ésta se sitúa junto a la Torre del Homenaje. La puerta estaba construida a base de sillares de caliza, bien trabajados, junteados con mortero fino de cal. La forma y tamaño de los sillares es diversa, destacando las piezas que forman parte de las jambas, especialmente las dos que configuran las mochetas, ya que están talladas en forma de "L", conteniendo una de ellas una quicialera tallada en el mismo bloque, donde además se conservan restos del extremo del gorrón de la puerta, realizado con hierro. En el otro lado del vano tenemos una quicialera labrada en una piedra exenta de la obra principal. Gracias a todo ello sabemos que el cortijo contaba con una puerta de doble hoja que se abría hacia dentro. La planta es abocinada: el frente más ancho es el interior con una luz de $2,40 \mathrm{~m}$, mientras que el exterior mide $1,63 \mathrm{~m}$ desde las mochetas, siendo la profundidad de la puerta de $1,85 \mathrm{~m}$. La obra de sillería conforma 
las jambas reforzadas de las que arranca un potente muro de mampostería con mortero de cal que se desarrolla en sentido norte y sur. El tramo sur acomete la Torre del Homenaje y se adosa al frente oeste de la misma. El tramo norte entesta contra un torreón muy deteriorado que tiene una disposición oblicua con respecto a la puerta y muro descritos y que aparece identificado en la visitación de 1480: "e fallaron a la entrada de la puerta, a la mano derecha, en el cortijo, vn torrejón que quedó de tiempo de los moros bueno de cal e canto maçiço". El torreón, que está construido asimismo con mampostería y mortero de cal y es macizo, cumple la doble función de proteger la puerta y reforzar el cambio de orientación de los lienzos que tiene a ambos lados. Para ascender al adarve existía una escalera de mampostería y cal que se adosaba al frente oriental del cortijo.

La crujía sur del cortijo está ocupada por los restos de un edificio rectangular de fábrica bien distinta que el resto, en este caso sillarejo tomado con mortero de cal, obra que parece contemporánea de la apertura de la nueva puerta del cortijo. Teniendo en cuenta las razones técnicas así como la lectura arqueológica que permite observar que se trata de una construcción posterior al resto, nos inclinamos por creer que se trata de la cuadra, cocina y cámara que se mandó construir en la visita de 1494 y que en 1507 ya es citada.

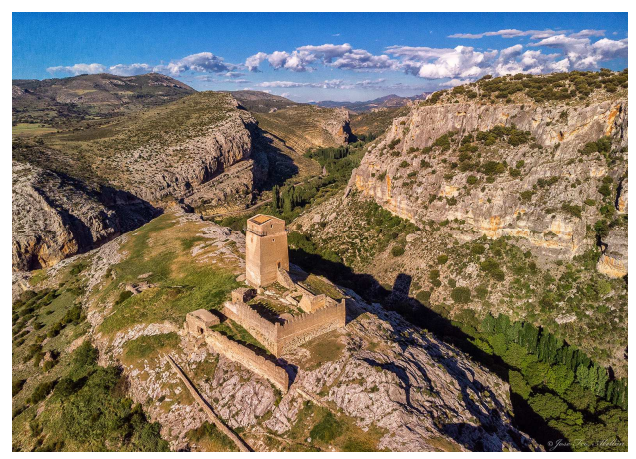

Fig. 7. La fortaleza de Taibilla (J. F. Abellán).

La Torre del Homenaje, un edificio singular tanto por su relevancia en el conjunto defensivo como por su buen estado de conservación, es una construcción de planta cuadrada y alzado prismático cimentada sobre la roca. Consta de 5 pisos: el inferior está ocupado por dos aljibes abovedados; el principal, que acoge la puerta de entrada; y otros tres superpuestos. El acceso a la Torre se realiza por un único vano de sillería situado en altura, subiéndose mediante una escala, según afirman las visitaciones, siendo hoy por una escalera reciente de mampostería que fue restaurada en los años 80 del siglo XX. La puerta presenta un arco de medio punto y se cerraba mediante dos hojas y tranca. Por su tipología la podemos adscribir a época bajomedieval, y vino a reemplazar a la puerta primigenia con arco de ladrillo, de cuya rosca interior aún se conservan algunos restos. Toda la fábrica de la Torre es de tapial de hormigón salvo la del último cuerpo, fabricado con mampostería tomada con cal. Éste último, acabado en una cubierta a dos aguas y circundado por un cadahalso o "guirnalda" de madera, es, claramente, un añadido a la obra original; llamada "la cabaña", ignoramos la fecha en que se construyó, aunque en la primera visitación conservada, la de 1460 , ya se menciona y se explica que se encontraba en estado ruinoso. Habían desaparecido tanto la cubierta a dos aguas, con que estaba rematada, como los forjados, escaleras, arcos y tabiquería del interior; mientras que del cadahalso sólo se conservaron en muy mal estado algunos de los canes que lo sostenían, que eran "de savyna e tejo" y que se desmontaron hace quince años cuando se acometió la restauración de la Torre.

\section{Interpretación y cronología}

El análisis arqueológico y documental de los restos defensivos descritos nos permite deducir que tanto el recinto exterior como el castillo son obras santiaguistas, a diferencia de lo que tradicionalmente se ha afirmado en la historiografía previa, que los atribuía a época andalusí. Las excavaciones arqueológicas efectuadas en 2004 permitieron documentar en el interior de la crujía sur del cortijo y por debajo del nivel de suelo, el basamento de un ancho muro de dirección este-oeste, hecho con mampostería tomada con mortero bastardo que efectivamente podría ser de época islámica, pero que nada tiene que ver con las construcciones que hemos descrito en este trabajo. En nuestra opinión, el recinto 
exterior correspondería a la muralla de la puebla o concejo cristiano, mientras que el castillo sería la residencia del comendador y luego del alcaide.
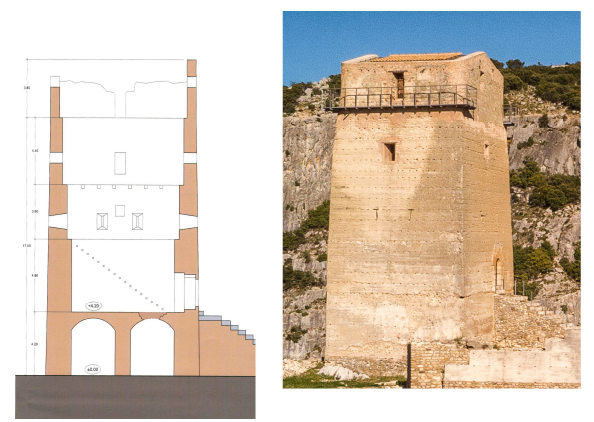

Fig. 8. Sección del proyecto de restauración de la Torre del Homenaje. ${ }^{7}$

El recinto exterior, el cortijo y la torre muestran una serie de semejanzas en cuanto a material constructivo y tamaño de los tapiales que parecen indicar que estamos ante un mismo proyecto constructivo. Además, los dos recintos estaban rematados mediante una combinación idéntica de pretil con saeteras y almenas con piramidón. Otro detalle que revela la similitud técnica de los dos recintos es el empleo en jambas y esquinas del cortijo de sillares de un tipo de piedra característico denominado atoba, que son idénticos a los que presentaban las jambas de la puerta en recodo del recinto exterior y de la puerta antigua. Las características de este vasto proyecto defensivo revelan la presencia de un poder político fuerte que tomó la determinación de construirlo en un momento puntual. Por todo ello y teniendo en cuenta la historia del yacimiento, nos inclinamos por creer que esta decisión se tomó en el año 1245, cuando la Orden de Santiago decidió constituir la encomienda de Taibi1la, generándose entonces unas especiales necesidades defensivas, pues se trataba de una minoría cristiana en un ambiente mayoritariamente mudéjar, y de representación, pues debía acoger la residencia permanente del comendador y de su pequeña corte. Esta obra nueva necesitó del derribo de las construcciones del encastillamiento islámico, del que apenas han quedado huellas. El recinto exterior estaba abandonado ya durante la segunda mitad del siglo XV, según demues- tran las referencias de los visitadores de la Orden (Rodríguez Llopis, 1982; Torres Fontes, 1965$1966)^{8}$, lo que, en consonancia con la hipótesis expuesta, se debería al proceso de despoblación que sufrió Taibilla durante el siglo XIV.

El proyecto constructivo sería muy similar, por ejemplo, al de la cercana encomienda de Socovos establecida en 1245: consta de un recinto amurallado inferior con "ocho torrejones" destinado a proteger la "villeta" en la que se encuentran las casas de los repobladores, mientras que en el centro "está la fortaleza ençima de vna penna alta" acogiendo la residencia del comendador, compuesta por la Torre del Homenaje y por el cortijo, tal y como es habitual en estos edificios. ${ }^{9}$

Además de las razones históricas comentadas, existen paralelos arquitectónicos de la gran torre de Taibilla en otros puntos del antiguo reino de Murcia que acreditarían la atribución y cronología que proponemos. Están documentadas tanto en fortalezas realengas, como las torres del Espolón y Alfonsina de Lorca, como santiaguistas, caso de Moratalla, Alhama o Aledo (Sánchez Pravia, 1999, 2016; Pozo Martínez, 2003; Ramírez Águila, Baños Serrano, 2005; Martínez López, Munuera Navarro, 2009).

Ésta última torre, como la de Taibilla, es una construcción de tapial, técnica típica de la arquitectura andalusí desde el siglo XII, por lo que parece lógico suponer que en ambos casos fueron alarifes musulmanes los que las levantaron, aunque bajo las directrices de los conquistadores. Otra prueba que nos permite adscribir la construcción a la Orden es un documento de 1347 en el que se ordena la construcción de un castillo en Bullas, lugar perteneciente en ese tiempo a la encomienda santiaguista de Caravaca, que describe un modelo o patrón de castillo compuesto por torre del homenaje y cortijo que se ajusta con precisión al ejemplo de Taibilla: "una torre con un cortijo enderredor della que sea de quinze tapiales en alto et que aya en ella tres terminados, et del çimiento della fasta el primero terminado que sea la tapia de ocho palmos en ancho, et del primero fasta el segundo terminado que sea la tapia de seys palmos en ancho, et del segundo terminado fasta el terçero 
terminado que sea dessa anchura la tapia. Et del dicho çimiento fasta el dicho primero terminado que sea la lavor de argamasa o de piedra et de cal, et los otros dos terminados de tierra et de cal. Et el cortijo que sea de diez tapiales en alto con su peytril et menas, et que sea la tapia de çinco palmos en ancho, et la lavor del cortijo que sea fecha de tierra et de cal"10 (Torres Fontes, 1982, pp. 133 y ss).

\section{Notas}

${ }^{1}$ Para el poblamiento islámico en la cuenca alta del río Segura, ver: Navarro Romero, 1998; Jiménez, et al., 2008-2009.

${ }^{2}$ Algunos autores apuntan que la plaza de Segura se conquistó en la campaña de 1239-1242.

${ }^{3}$ 1243. Privilegio rodado del infante don Alfonso por el que concede a Pelay Pérez Correa, maestre de la Orden de Santiago, y a García Lorenzo, comendador de Uclés, y a todos sus freiles y sucesores las fortalezas y aldeas comprendidas en el término de Segura de la Sierra. ES.30030.AGRM/FR,3 / Archivo Histórico Nacional, FR,3.2. / Órdenes Militares. FR,3.2.1. / Orden de Santiago, FR,3.2.1.1. / Archivo General del Convento de Uclés (Cuenca), FR,AHN,R-8/13; 1271. Avenencia entre Pelay Pérez, maestre de Santiago, y el Obispo de Cartagena, sobre los diezmos de las heredades de Lorca, Murcia, Orihuela, Aledo, Galera, Huéscar, Miravet, Volteruela, Moratalla, Orce, Castril, Bugéjar, etc. ES.30030.AGRM/FR,17 / Catedral de Murcia, FR,ACM,R-1/16; Chaves, 1740, p. 194b; Torres Fontes, 1965, p. 327; Rodríguez Llopis, 1982, p. 53.

${ }^{4}$ Confirmada en 1305 (Ibid) y 1316 (Matellanes Merchán, 1993, p. 133).

5 Descripción de Simón López García, en Lozano Santa, 1749)

${ }^{6}$ Ver como referencias para su descripción las visitaciones de la Orden de Santiago recogidas en el apartado de bibliografía, además del libro sobre la encomienda de Yeste-Taibilla de Miguel Rodríguez Llopis (1982). Asimismo, la historiografía referente a Taibilla es la siguiente: Lozano Santa, 1794; Ceán Bermúdez, 1832; Amador de Los Ríos, 1912; Torres Fontes,
1965-1966; Lillo Carpio, Molina Molina, 1981; Rodríguez Llopis, 1982; Jiménez Castillo, Muñoz López, 2005; Simón García, 2011; Frey Sánchez, 2014; García, et al., 2016.

7 Estudio Garví y Moro, sobre propuesta de Pedro Jiménez y Francisco Muñoz.

${ }^{8}$ Véanse las transcripciones de las visitas santiaguistas de 1468, 1480, 1494 y 1507.

1498. Libro de visitas de la Orden. YesteTaibilla. ES.30030.AGRM/FR,3 / Archivo Histórico Nacional, FR,3.2./ Órdenes Militares, FR,3.2.5./ Real Consejo de las Órdenes Militares, FR,3.2.5.1./ Serie de la Orden de Santiago, FR,3.2.1.1.1. / Visitas a los territorios de la Orden de Santiago, FR,AHN,R-1/5.

${ }^{9}$ Sobre la fortaleza y villa de Socovos, véanse las acertadas observaciones de Fernández Baudín 1961, pp. 2-45; existe una monografía relativamente reciente, (Eiroa Rodríguez, 2004), en la que se publican los textos de las visitas santiaguistas, lo que resulta de gran utilidad; discrepamos, no obstante, de algunas de las interpretaciones de este investigador, especialmente de su identificación del castillo del comendador con el conjunto de dos recintos, en el que nosotros distinguimos, a la luz de los textos y de lo conservado, la puebla (el recinto externo) y, en el centro y sobre la roca, el castillo propiamente dicho. Los restos de muros en la huerta, que Eiroa supone pertenecen a la muralla de la villa cristiana, entendemos que corresponden a un albercón, del que, de hecho, aún es posible identificar un acueducto que lo alimentaba.

${ }^{10}$ En 1338 Alfonso XI entrega 10000 maravedís para el arreglo de diversos castillos del reino de Murcia, entre ellos Cehegín; poco después, en 1344, la bailía de Caravaca pasa a manos de la Orden de Santiago (Marín Ruiz de Asín, 2013, pp. 86, 88) y en 1347 el nuevo comendador Ruiz Chacón proyecta la reconstrucción del castillo de Bullas, pero en los años siguientes el reino se ve afectado por la peste y no parece que pudiera cumplir el compromiso (Torres Fontes, 1982, p. 113). En 1352 Pedro I ordena al Maestre D. Fadrique que repare los castillos de Caravaca y Cehegín, "que están derribados e yermos, de tal manera, que sy guerra ouiese serian a gran peligro de se perder [...]" (Molina Molina, 2002, p. 125). 


\section{Bibliography}

Aguado de Córdoba, A.F.; Alemán Et Rosales, A.A.; López Agurleta, D.J., ed. (1719). Bullarium equestris ordinis S. Iacobi de Spatha per annorum seriem nonnullis Donationum - alijs interiectis Scripturis, Madrid, in http://biblioteca.galiciana.gal/es/consulta/registro.cmd?id=6270.

Ceán-Bermúdez, J.A. (1832). Sumario de las antigüedades que hay en España, en especial las pertenecientes á las Bellas Artes, Madrid.

Chaves, B. (¿1740?). Apuntamiento legal sobre el dominio solar de la Orden de Santiago en todos sus pueblos, ¿Madrid?, in https://bibliotecadigital.jcyl.es/es/consulta/registro.cmd?id=4123.

Eiroa Rodríguez, J. (2004). Arqueología e historia de la fortaleza medieval de Socovos, Instituto de Estudios Albacetenses (IEA), Serie I, $\mathrm{n}^{\circ}$ 154, Albacete.

Fernández Baudín, C. (1961). "Datos para la historia de la villa de Socovos", Revista de Estudios Regionales La Mancha, 4, pp. 2-45.

Frey Sánchez, A.V. (2014). Castillos y territorio del alto Segura. Arquitectura defensiva y poblamiento entre los siglos XII y XIV, libro digital, ed. González Palencia, Murcia.

García, A.T.; Nieto, P.; Noval, R. (2016). "El Castillo de Taibilla, Nerpio (Albacete). Proyecto para su puesta en valor", in Gamo Parras, B.; Sanz Gamo, R., coords., I Reunión Científica de Arqueología de Albacete, IEA, Serie III, n 16 , pp. 141-150.

Guichard, P. (1991). L'Espagne et la Sicile musulmanes aux XI ${ }^{e}$ y XII ${ }^{e}$ siècles, Presses Universitaires Lyon.

Hadj-Sadok, M. (1968). "Kitiib al-Dja'riifiyya. Mappemonde du calife al-Ma'mün reproduite par Faziiri: (IIIe/IX' s.) rééditée et commentée par ZuhrI (Vle/XII' s.)", Bulletin d'Études Orientales, XXI, pp. 7-312.

Huici Miranda, A. (1956). Historia política del Imperio Almohade, Tetuán.

Jiménez Castillo, P.; Muñoz López, F. (2005). "Excavación arqueológica y restauración del castillo de Taibilla", Revista de Taibilla, 11, Nerpio, pp. 28-32.

Jiménez, P.; Muñoz, F.J.; Simón, J.L.; Segura, G. (2008-2009). Cartas arqueológicas de los municipios de Nerpio, Yeste, Letur, Socovos y Férez, Empresa ARQUEALIA (Trabajos de Patrimonio Cultural S.L.), Consejería de Cultura, Junta de Comunidades de Castilla - La Mancha.

Lillo Carpio, P.; Molina Molina, A.L. (1981). "El castillo de Taibilla", Miscelánea Medieval Murciana, 7, pp. 82-74.

López Fernández, M. (2004). "Las incursiones sobre las tierras albaceteñas en otoño de 1241y primavera de 1242", Al-Basit, 42, pp. 33-51.

Lozano Santa, J. (1794). Bastitania y Contestania del Reino de Murcia, reimpresión facsímil, vols. I, II y III, Academia Alfonso X El Sabio, Murcia, Edic. 1980.

Marín Ruiz De Assín, D. (2013). Caravaca 1243-1516. Una villa santiaguista en la frontera de Granada, Tesis Doctoral, Universidad de Murcia, Murcia.

Matellanes Merchán, J.F. (1993). "La hospitalidad en la Orden de Santiago: un proyecto ideológico o económico (1170-1350)”, Studia historica. Historia medieval, 11, pp. 125-140.

Molina López, E. (1972). La cora de Tudmîr según al-`Udrî (s. XI). Aportaciones al estudio geográfico-descriptivo del SE. Peninsular, Cuadernos de Historia del Islam n ${ }^{\circ} 4$, (serie monográfica $\mathrm{n}^{\circ} 3$ ).

Molina Molina, A.L. (2002). "Evolución urbana de Cehegín de la Edad Media a 1850", in Estudios históricos y geográficos para la recuperación de los cascos históricos del Noroeste de la Región de Murcia, Murcia, pp. $123-142$.

Navarro Romero, C. (1998). "Fortificaciones y asentamientos andalusíes en la actual provincia de Albacete: un alAndalus textualmente casi invisible", in Barceló, M.; Tourbert, P., drs., L'Incastellamento, Roma, pp. 205-231.

Pozo Martínez, I. (2003). "El castillo-fortaleza de Moratalla", Murgetana, 109, pp. 19-47.

Ramírez Águila, J.A.; Baños Serrano, J. (2005). "El castillo de Alhama de Murcia: una fortaleza castellana entre Aragón y Granada”, Verdolay, 9, pp. 255-274.

Rivera Garretas, M. (1985). La Encomienda, el Priorato y la Villa de Uclés en la Edad Media (1174-1310), Consejo Superior de Investigaciones Científicas (CSIC). 
Rodríguez Llopis, M. (1982). Conflictos fronterizos y dependencia señorial: La encomienda santiaguista de Yeste y Taibilla (ss. XIII-XV), IEA-CSIC, Serie I, $\mathrm{n}^{\circ}$ 9, Albacete.

Rodríguez Llopis, M. (1985). "La Expansión territorial castellana sobre la cuenca del Segura (1235-1325)", Miscelánea Medieval Murciana, 12, pp. 105-138.

Rodríguez Llopis, M. (1986a). "Repoblación y organización social del espacio en los señoríos santiaguistas del reino de Murcia (1235-1350)", Murgetana, LXX, pp. 5-34.

Rodríguez Llopis, M. (1986b). Señoríos y feudalismo en el Reino de Murcia. Los dominios de la Orden de Santiago entre 1440 y 1515, Editora de la Universidad de Murcia (EDITUM).

Rodríguez Llopis, M. (1991). Documentos de los siglos XIV y XV. Señorío de la orden de Santiago, vol. XVII de la Col. De Documentos para la Historia del reino de Murcia, Academia Alfonso X El Sabio, Murcia.

Rodríguez Llopis, M. (1995). "El privilegio de villazgo de Nerpio y su segregación de Yeste", Cultural Albacete, 87 ( $2^{\circ}$ Época), Albacete, pp. 3-14.

Ríos, A. de los; Fernández de Villalta, R. (1889). Murcia y Albacete. Españaa, sus monumentos y artes, su naturaleza e historia, Barcelona.

Sánchez Pravia, J.A. (1999). "La Torre del Homenaje de la villa de Aledo. Realidad y ensueño", Memorias de Arqueología, 9, Murcia, pp. 402-414.

Sánchez Pravia, J.A. (2016). Estudio histórico-arqueológico de Aledo y Totana en los siglos XV y XVI, Tesis Doctoral, Universidad de Murcia, Murcia.

Simón García, J.L. (2011). Castillos y Torres de Albacete, IEA, Serie I, nº 200, Albacete.

Simón García, J.L. (2016). "El poblamiento medieval en Albacete: alquerías y castillos”, in Gamo Parras, B.; Sanz Gamo, R., coords., I Reunión Científica de Arqueología de Albacete, IEA, Serie III, nº 16, pp. 659-682.

Torres Fontes, J. (1965). "La regencia de don Fernando el de Antequera y las relaciones castellano-granadinas (14071416)", Miscelánea de estudios árabes y hebraicos. Sección Árabe-Islam, 14, pp. 137-167.

Torres Fontes, J. (1965-1966). "Los castillos santiaguistas del Reino de Murcia", Anales de la Universidad de Murcia, XXIV, 3-4, pp. 325-348.

Torres Fontes, J. (1982). Documentos para la historia medieval de Cehegín, Academia Alfonso X el Sabio, Murcia.

Vallvé Bermejo, J. (1972). "La división territorial en la España Musulmana (II). La cora de Tudmir (Murcia)", AlAndalus, 37, 1, pp. 145-190. 